\title{
Prensa, deporte y cultura de masas. El papel del periodismo especializado en la expansión social del deporte en Cataluña hasta la guerra civil (1890-1936)
}

\author{
Xavier PuJADAS I MARTí \\ Universitat Ramon Llull \\ xavierpm@blanquerna.url.edu \\ Carles Santacana i Torres \\ Universitat de Barcelona \\ carles.santacana@ub.edu
}

Recibido: 20 de julio de 2012.

Aceptado: 2 de octubre de 2012.

\section{Resumen}

Este artículo tiene como objetivo analizar el rol de la prensa deportiva en el proceso de institucionalización y expansión del fenómeno deportivo en Cataluña entre 1890 y 1936. El estudio es resultado de un exhaustivo análisis previo sobre el conjunto de cabeceras deportivas del período, tanto en lo que se refiere a su contenido formal como desde una visión empresarial. En definitiva, se plantean respuestas sobre tres aspectos clave: (a): el relevante papel de la prensa doctrinaria de finales del s. XIX en la inicial extensión de la cultura deportiva, (b): la vinculación entre prensa deportiva y moderna industria del ocio deportivo y (c): la importancia de la prensa de masas en la definitiva popularización deportiva de las décadas de 1920 y 1930.

Palabras clave: Deporte; periodismo deportivo; cultura de masas; historia de Cataluña.

\section{Press, sport and mass culture. The role of specialized journalism in the social growth of sport in Catalonia until the civil war (1890-1936)}

\begin{abstract}
This paper aims to analyze the role of the sports press in the process of institutionalization and expansion of the sporting phenomenon in Catalonia between 1890 and 1936. The study is a result of a comprehensive preliminary analysis of sports journals of the period, both as regards their formal content as from a commercial approach. In short, the paper discusses three key aspects: (a): the important role of the press of late 19th century in the initial spread of sporting culture, (b): the link between the modern sports media and sports leisure industry, and (c): the importance of mass media in popularizing the sport in the decades of 1920 and 1930.
\end{abstract}

Key words: Sport; sports journalism; mass culture; history of Catalonia.

\section{Referencia normalizada}

Pujadas i Martí, X., Santacana i Torres, C. (2012). Prensa, deporte y cultura de masas. El papel del periodismo especializado en la expansión social del deporte en Cataluña hasta la guerra civil (18901936). Historia y Comunicación Social, Vol. 17, páginas 141-157.

Sumario: 1. Introducción. 2. La formación de un espacio comunicativo propio (1890-1913). 3. Hacia la prensa deportiva de masas (1914-1920). 4. Llega el espectáculo: masificación deportiva y prensa popular (1920-1936). 5. Conclusiones: la prensa como factor de extensión deportiva. 6. Bibliografía. 


\section{Introducción}

El inicio del proceso de incorporación e institucionalización de la práctica de los deportes modernos de origen inglés en España se produjo sobre todo a partir del último tercio del siglo XIX. Fue precisamente en ese periodo, y no en etapas anteriores, cuando se desarrolla un inicial asentamiento y ramificación de la cultura deportiva (Domínguez Almansa, 2011: 55-57). Indudablemente, se trata de un fenómeno fundamentalmente urbano, y vinculado a determinadas ciudades industriales y comerciales en las que, no solo existe un flujo de ciudadanos de diferentes procedencias, sino que emerge una demanda real acerca de un modelo de ocio moderno, burgués y vinculado a la actividad física. Durante los últimos decenios del siglo XIX, en consecuencia, este proceso se produjo especialmente en zonas donde confluía la aparición de colonias de ciudadanos extranjeros con la preexistencia de una demanda autóctona acerca de los nuevos hábitos de la moderna cultura del ocio físico deportivo, lo cual, en el caso catalán, es claramente detectable desde 1860 (Pujadas, 2004: 646-647).

Sin embargo, la extensión de una cultura deportiva en Cataluña en la segunda mitad del siglo XIX - entendiendo por cultura deportiva un conjunto de comportamientos, hábitos, actitudes, valores y un sistema de símbolos y normas estrechamente vinculados al estilo de vida de la moderna burguesía industrial anglosajona (García Ferrando, Lagardera y Puig, 1998:77)- requirió de una activa red asociativa y de una prensa interesada en difundir el fenómeno, bien como una forma de extender los valores deportivos por parte de las asociaciones, o bien como una respuesta natural a la existencia de una demanda creciente de información sobre deporte. Sea como fuere, y a pesar de la temprana existencia de boletines relacionados con el mundo del excursionismo en la década de $1870^{1}$, la aparición de cabeceras especializadas en deporte en Cataluña con una clara vocación de divulgar las instituciones y valores deportivos, debe situarse a partir del inicio de la década de 1890 (Berasategui, 2000: 157; Figueres, 1992:25).

Desde la perspectiva de la historia social del deporte y de la historia de la comunicación, es muy relevante tener en cuenta en qué medida y de que maneras la prensa deportiva influyó en la expansión de la práctica, en la consolidación de una cultura deportiva y en el despliegue de un discurso propio creador de una industria ascendente durante el primer tercio del siglo XX. De hecho, este rol de la prensa en la difusión histórica de lo deportivo ha sido tratado en los casos norteamericano y británico, teniendo en cuenta la importancia del periodismo deportivo y de los periodistas en la génesis y desarrollo de un interés popular por el deporte (Riess, 1995:29) y en la difusión de una cultura de la industria del deporte (Harvey, 2004). Parece evidente, en todo caso, que en el período inicial de difusión de las prácticas deportivas en Inglaterra, la prensa se convirtió en una de las principales herramientas de promoción para "los impulsores de la industria del ocio público" (Rowe, 2008:31). En España, si bien mucho más tardía su aparición, la prensa deportiva -y también las secciones deportivas de la prensa general- ayudaron de manera decisiva a convertir a los protagonistas del deporte en lo que algunos autores han denominado élites 
simbólicas o "representantes de valores ampliamente compartidos" entre los ciudadanos (Uría, 2008: 160), como mínimo en algunas prácticas concretas como el fútbol, el boxeo y el ciclismo y, sobre todo, a partir de 1920.

En consecuencia, el objeto fundamental de este trabajo ha sido analizar el papel jugado por la prensa especializada en deportes en Cataluña en el proceso de institucionalización y expansión de la práctica y la cultura deportivas entre 1890 y 1936 , con la intención de entender mejor la influencia de la prensa en la construcción de un universo simbólico y cultural deportivo propio a principios del siglo XX, en la posterior difusión de la actividad deportiva y de su mercantilización como industria del ocio, y en la popularización del deporte de las décadas de 1920 y 1930.

Para abordar dicho objeto de estudio, se ha analizado el contenido de una muestra representativa de 16 cabeceras deportivas editadas en Cataluña durante el período 1890-19362, con el objetivo de establecer una relación significativa entre el contenido formal, línea editorial, estructura institucional y comercial de la cabecera con el proceso de institucionalización y desarrollo del fenómeno deportivo en Cataluña. Este análisis, partía de un proyecto de investigación más amplio que ya dio sus frutos a los autores del presente artículo con resultados generales que fueron difundidos en una publicación precedente sobre el periodismo deportivo catalán entre 1880 y 1992 (Pujadas y Santacana: 1997). El análisis de las cabeceras apuntadas, ha sido completado con fuentes de tipo bibliográfico acerca del contexto socio deportivo y periodístico catalán, español e internacional, así como con otros resultados de estudios posteriores realizados por los autores.

\section{La formación de un espacio comunicativo propio (1890-1913)}

Durante la década de 1890 el fenómeno deportivo barcelonés vivió un proceso de eclosión pública que, sin duda, debe vincularse a la expansión de los deportes de origen inglés posterior a la celebración de la Exposición Universal de 1888 (Torrebadella, 2012: 87). Disciplinas como el tenis, el fútbol, el polo, el remo, la esgrima, el ciclismo y en menor medida el atletismo, eran practicadas por sectores de ciudadanos extranjeros y autóctonos que, a lo largo de la década, propiciaron la creación de sociedades deportivas y, en consecuencia, la institucionalización inicial del deporte moderno. Si bien resulta evidente que las actividades físicas de carácter gimnástico y excursionista ya se habían desarrollado anteriormente en el contexto urbano moderno de la Barcelona de las décadas de 1850 a 1870 (Roma, 1996: 26; Subirats, 2004: 626; Pujadas, 2012: 4), fue gracias a la extensión de los deportes atléticos que asistimos a la aparición de una red asociativa precursora de un espacio comunicativo deportivo propio, con características similares a las de la prensa deportiva ya existente desde los albores del siglo XIX en Inglaterra (Harvey, 2004). En el caso de Barcelona, la existencia desde la década de 1850 de una incipiente industria del ocio vinculado a las disciplinas corporales -caso de los espectáculos acrobáticos, los baños en la playa y las mesas de billar- facilitó la adaptación de los deportes atléticos a partir de $1890 \mathrm{y}$, en consecuencia, el desarrollo de una cultura deportiva que 
requería de plataformas comunicativas para su reproducción. Dado que el proceso de institucionalización del fenómeno deportivo moderno en Cataluña reprodujo en buena medida el modelo asociativo británico, este espacio comunicativo inicial de la cultura deportiva se desarrolló fundamentalmente a través de los clubs y asociaciones, y de sus órganos de información. Sobre todo, de aquellos que tenían relación con deportes cercanos a una actividad de tipo comercial que podía alimentar la floreciente demanda de ocio urbano moderno, bien como espectáculo deportivo y de apuestas o bien como industria, por ejemplo en el caso de la bicicleta. No debe extrañar, por lo tanto, que estas primeras cabeceras deportivas tuvieran una función utilitaria, de información sobre las actividades periódicas de los asociados, de carácter institucional en relación a las entidades representadas y, a su vez, de difusión de los reglamentos y de otros aspectos técnicos relacionados con las disciplinas a las que estaban vinculadas. Se trataba de publicaciones periodísticas cercanas a lo que puede denominarse como adoctrinamiento deportivo (Pujadas y Santacana, 1997: 13) en un contexto de inicial difusión de las prácticas, en el que resultaba imprescindible informar regularmente sobre las actividades deportivas para los asociados y, a la vez, extender los códigos fundamentales de la cultura del deporte moderno.

En el caso catalán, las primeras cabeceras especializadas que son representativas de este incipiente periodismo doctrinario, estaban vinculadas a la importante expansión del ciclismo y del frontón, que se produjo durante la primera mitad de la década de 1890. En el ámbito ciclista, debe tenerse en cuenta la aparición de entidades como el Club Velocipédico (1884), fundado por el industrial Claudio de Rialp i Navinés, y del Veloz Club de Barcelona (1887), así como la influencia del ciclismo francés en la articulación de una red asociativa importante ya en 1891. Entre 1888 y 1891 fueron creadas entidades ciclistas en poblaciones como Girona, Figueres, Olot, Sabadell, Terrassa, Mataró, Valls, Tortosa, Reus o Tarragona (Lagardera, 1991). Los ejemplos inglés y francés, en el caso de la publicación de The Cyclist (1879) y Vélocipède (1868), incidieron en la edición de las primeras cabeceras ciclistas catalanas en 1891 y 1892, que en buena medida reflejaban el modelo de expansión de un tipo de prensa ligada al desarrollo técnico e industrial del deporte, impulsada por los clubs y los industriales del sector. Un modelo que en Inglaterra había generado la publicación de The Cyclist, propiedad del industrial Henry Sturmey y una de las cabeceras relevantes para entender la articulación de la moderna cultura ciclista en la segunda mitad del siglo XIX (Brake y Demoor, 2009: 156). Así pues, entre las primeras publicaciones deportivas de la década deben ser citadas la revista quincenal El Ciclista (1891), aparecida como órgano de la Sociedad de Velocipedistas de Barcelona, La Velocipedia (1892), Revista de Sport (1895) y El Veloz (1895), editadas en Reus y vinculadas a las asociaciones ciclistas locales, y la barcelonesa $L a$ Bicicleta (1896). El Ciclista, que adoptaba de manera mimética el nombre del semanario británico antes aludido, fue fundada por el industrial y promotor del ciclismo Claudio de Rialp con el subtítulo de "Revista de Sport Nacional y Extranjero", y se erigió en la cabecera ciclista más relevante del período. Nacida con el propósito de divulgar los hábitos del ocio deportivo entre los sectores acomodados urbanos -entre 
los cuales también "los bailes de sociedad, las revistas de espectáculo notables y las reseñas de soirées del mundo aristocrático"3- jugó un papel importante en la institucionalización del ciclismo y en la creación de la Unión Velocipédica Española (1896), impulsada desde la revista por Claudio de Rialp y que él mismo acabaría presidiendo. Subtitulada, a partir de 1892, como "Revista de Sport", El Ciclista mantuvo secciones fijas de remo, esgrima y regatas, y se convirtió en una referencia en el todavía escaso y elitista universo deportivo de la época. La aparición en la población de Reus de Revista de Sport y El Veloz en 1895, por otro lado, indicaba la extensión del asociacionismo ciclista y deportivo fuera de Barcelona y, a la vez, iniciaba un periodismo local especializado que tendría un calado importante en la prensa deportiva catalana posterior (Pujadas y Santacana, 1996: 37). La extensión real del periodismo incipiente dedicado a la bicicleta a finales del siglo XIX, sin embargo, fue menor de lo que podría sospecharse a la luz del número de cabeceras deportivas aparecidas en la capital catalana (ver tabla 1), ya que en realidad se trataba de un mercado socialmente cautivo, elitista y alejado de la realidad sociodeportiva de países que eran tomados como referencia, caso de Inglaterra, Francia o Bélgica. Si bien algunas publicaciones, como La Bicicleta en 1896, afirmaban tirar 6.000 ejemplares (La Bicicleta, 21-01-1896), a finales de la década el balance era escasamente alentador, dado que "hoy por hoy" el número de aficionados en España no hace posible "el sostenimiento de ningún diario dedicado exclusivamente al sport cíclico, como en el extranjero"4.

El nuevo mercado periodístico deportivo de 1890, no obstante, encontró una segunda vía de expansión a través de las publicaciones ligadas al espectáculo y las apuestas generadas por el auge del frontón en la ciudad de Barcelona a partir de la apertura del primer local -el Frontón Barcelonés- en 1893. Se trataba de un ámbito comunicativo diferenciado del anterior, a pesar de compartir un sector de público urbano, acomodado y cercano al ocio deportivo moderno, que contaba con un lector fiel que buscaba información sobre los jugadores, los resultados y las apuestas y que estaba íntimamente ligado a la actividad comercial de la pelota. Entre 1893 y 1896, en Barcelona aparecieron cuatro publicaciones sobre este juego, que reflejan la vitalidad de la progresiva transformación de los hábitos de consumo burgués hacia las actividades vinculadas al espectáculo deportivo. Se trata de El Frontón (1893), La Cancha (1895), La Cesta (1896) y El Pelotari Cómico (1896), probablemente el primer intento cómico periodístico de temática deportiva en Cataluña, que intentaba combinar la crónica seria con el comentario jocoso sobre los avatares del juego.

Tabla 1. 1880-1913. Aparición de cabeceras deportivas nuevas en Barcelona y Cataluña.

Fuente: Elaboración propia

\begin{tabular}{|l|l|l|l|}
\hline Años & Barcelona & Cataluña & Total \\
\hline $1880-1890$ & 3 & 0 & 3 \\
$1891-1900$ & 14 & 3 & 17 \\
$1901-1910$ & 17 & 0 & 17 \\
$1911-1913$ & 11 & 0 & 11 \\
\hline Totales & $45(94 \%)$ & $3(6 \%)$ & $48(100 \%)$ \\
\hline
\end{tabular}


Al final de la década de 1890 y durante el primer decenio del Novecientos, el fenómeno deportivo en Cataluña ya había encontrado buena parte de la red de difusión necesaria que lo haría crecer socialmente hasta la guerra civil. Tal y como afirma Bahamonde (2011: 95-96), el desarrollo del deporte entre 1900 y 1936 en España no solo se encontraba asociado a la modernización económica, sino que formaba parte de ella. Muchos de los aspectos vinculados a eses proceso, como el crecimiento del producto industrial, el incremento del sector servicios y del sector exterior dieron lugar, en Cataluña, al crecimiento urbano y de la demanda de un nuevo modelo de ocio ligado a la activa burguesía autóctona y a sectores de profesionales liberales, periodistas y educadores interesados en impulsar el asociacionismo deportivo privado. Sin duda alguna, este contexto de extensión del deporte-que se puede ilustrar con el auge del fútbol y la creación de la Federación Catalana de este deporte (1900)- se encontraba estrechamente relacionado con el desarrollo, por primera vez, de un sistema comunicativo deportivo articulado profesionalmente, más diversificado en la oferta, menos determinado por la red asociativa, construido sobre bases empresariales y más maduro en las formas y los estilos comunicativos, si bien conservando todavía el carácter de apostolado. En realidad, se trata del inicio del proceso de profesionalización del periodismo deportivo catalán y, en buena medida, español, que culminó en junio de 1911 con la creación del primer Sindicato de Periodistas Deportivos en Barcelona (Navarro, 1916: 13-18). No obstante, aquello que mejor define las características de este proceso es la aparición de algunas cabeceras que renovaron formalmente el discurso periodístico deportivo y su formulación empresarial, llegando a nuevos sectores sociales y consolidando las bases de la transformación posterior a 1914.

En este sentido, es imprescindible hacer referencia a la publicación de tres periódicos barceloneses que jugaron un papel fundamental en la difusión de las actividades deportivas del cambio de siglo: Los Deportes (1897), El Mundo Deportivo (1906) y Stadium (1911). El primero de ellos nació en el Gimnasio Solé de la mano del periodista Narcís Masferrer i Sala en colaboración con el propietario del gimnasio, Francesc Solé. Los dos crearon la Asociación Catalana de Gimnasia y el periódico, inicialmente ligado a la citada entidad y a la Federación Gimnástica Española (Los Deportes, 28-04-1906). En 1899, la revista se consolidó como la cabecera deportiva más importante en Cataluña, se fusionó con Barcelona Sport, se convirtió en semanario, diversificó el contenido informativo e inició la organización de competiciones deportivas, ya que "a medida que mayor desarrollo vaya adquiriendo Los Deportes, mayor y más grande importancia tomarán nuestras sociedades existentes, se crearán otras nuevas y marcharemos por la senda interminable de este progreso" (Los Deportes, 7-05-1899). El paso decisivo del semanario, sin embargo, se produjo en septiembre de 1899 con la creación de la Sociedad Los Deportes, empresa integrada por diversos promotores y directivos deportivos de la ciudad que tenía como objetivo sostener la publicación y profesionalizar la organización de eventos deportivos. Se trataba de la primera experiencia empresarial de una revista deportiva -"nunca emprendimos una empresa en crear nuestros Deportes", reconocía Masferrer en agosto de 1899- con objetivos de rentabilidad económica y vinculada 
al desarrollo de la industria del ocio deportivo en la ciudad (Los Deportes, 20-081899). La aventura comercial de la revista obtuvo buenos resultados y el semanario perduró durante más de diez años, habiendo jugado un rol importante en la expansión competitiva e institucional del deporte, incluso participando en la formación de sociedades como el FC Barcelona en noviembre de1899.

La creación de El Mundo Deportivo en 1906 y de la revista Stadium cinco años más tarde, tiene un significado decisivo en el triple proceso de divulgación del fenómeno deportivo en Cataluña, de modernización formal del periodismo especializado $\mathrm{y}$, en fin, de avance hacia la profesionalización de la prensa de deportes española. En el caso de El Mundo Deportivo, en gran medida, porque recogió la experiencia de su director Narcís Masferrer -que había abandonado Los Deportes- y la unió a la visión empresarial de Jaume Grau i Castellà, que actuó como primer propietario y gerente. Junto a un equipo de redactores solvente, Masferrer planteó una línea editorial abierta a las nuevas tendencias de la moderna cultura deportiva, del turismo, la industria automovilística i ciclista, la higiene y la formación física, sin olvidar las disciplinas atléticas de origen anglosajón. El resultado era una publicación semanal diversificada, con aportaciones literarias de gran nivel -Vicente Blasco Ibáñez y Odón de Buen, entre otros-, una importante presencia de publicidad de la industria del motor, y una renovada visión política y económica en el discurso doctrinario deportivo (Pujadas y Santacana, 1996: 24). Con una tirada inicial de 6.000 ejemplares, llegó a tirar 10.000 durante el primer año. Construida sobre una base empresarial sólida que permitía su autofinanciación gracias a la publicidad y a las ventas, entre 1906 y 1913 la revista pudo interesar a un público heterogéneo, que incluía a los practicantes, promotores, industriales y neófitos. Inspirándose en la experiencia organizativa de L'Auto, el semanario catalán impulsó la realización de grandes competiciones como la Carrera automovilística Barcelona Madrid de 1906 (El Mundo Deportivo, 5-04-1906). La revista Stadium, por su parte, supuso la primera creación en el periodismo deportivo catalán de de un magazine quincenal, profusamente ilustrado con 16 páginas fotográficas y con un despliegue inédito de corresponsales en Madrid, París y todas las capitales de provincia "donde el movimiento deportivo se halle suficientemente desarrollado" (Stadium, 05-1911). Dirigido por el deportista, promotor y publicista Ricard Cabot i Montalt, Stadium obtuvo una inicial "acogida excelente, extraordinariamente favorable" (Stadium, 061911), si bien la magnitud económica de la propuesta obligó rápidamente a buscar nuevos lectores fuera de Cataluña, lo cual se materializó en un suplemento semanal de ámbito español, la ampliación de anunciantes y nuevas corresponsalías en Madrid, San Sebastián, Vigo, Bilbao, Valencia y La Coruña, experiencia que resultó fallida a los pocos meses (Stadium, 1-06-1912).

Sin embargo, el peso de la sección ilustrada, la substitución del viejo discurso doctrinal por un tipo de crónica mundana y de sociedad, y la búsqueda de un mercado más amplio, reflejaba ya la aparición de nuevas tendencias que serían exitosas en la década posterior, merced a la masificación del espectáculo deportivo y a la popularización progresiva de su práctica. 


\section{Hacia la prensa deportiva de masas (1914-1920)}

El proceso de aparición y cristalización inicial de un modelo de prensa moderna e industrial en España se produjo en los años posteriores al estallido de la Primera Guerra Mundial. Dicha transformación trajo consigo el progresivo abandono de la prensa de carácter decimonónico, predominantemente ideológica, y la efervescencia del nuevo modelo de la prensa de masas "concebida como negocio, con una variedad temática de carácter enciclopédico, que pretende satisfacer los más diversos intereses de una gran y heterogénea cantidad de lectores" (Seoane y Saiz, 2007: 174). Si bien, en realidad, ese tipo de cambios no se consolidarían hasta entrada la década de 1920, se debe tener en cuenta que se trata de un proceso que empieza a emerger en los años de la Gran Guerra (Gómez Mompart, 1992). De hecho, algunos ámbitos informativos vinculados a las formas modernas de la cultura industrial - caso del deporte y de otros espectáculos- mostraron rápidos signos de transformación durante el período bélico iniciado en 1914, ya que en sí mismos representaban una parte importante de lo que la prensa moderna estaba asumiendo como propio, es decir, entretenimiento y espectáculo. El marco cronológico de 1914 a 1920, por lo tanto, puede ser contemplado como una fase de transición para el periodismo deportivo en el que ya se vislumbran algunas de la bases de la masificación posterior: modernización empresarial, aparición de estilos informativos más ágiles, protagonismo gráfico y publicitario, información profusa del extranjero, estructuración en secciones, profesionalización de los redactores y creciente presencia de periódicos en ciudades medianas (ver tabla 2) (Pujadas y Santacana, 1997:31).

Sin duda alguna, esta metamorfosis del periodismo especializado debe ser entendida en el contexto de los cambios sociodeportivos del período, que en Cataluña se materializaron en un incremento de la presencia pública del deporte a partir de 1910, así como de los efectos de la coyuntura de la guerra en Europa, que aceleró la necesidad de racionalizar el mercado de este género. En lo que se refiere al incremento de la práctica deportiva y de la oferta competitiva, deben tenerse en cuenta varios aspectos que tuvieron una incidencia real en el crecimiento del consumo de deporte $\mathrm{y}$, en consecuencia, en la demanda de información deportiva. Por un lado, la proliferación asociativa deportiva en cuanto a los clubes registrados, que solo en la ciudad de Barcelona se triplicó entre los años de 1914 a 1920 (Pujadas y Santacana, 1994:88). No debe olvidarse, además, que esta progresión asociativa presenta algunas características relevantes, como la creciente aparición de plataformas de carácter popular, o la consolidación de prácticas deportivas minoritarias, caso de la creación de la Federación Atlética Catalana en 1915. Sirva de ejemplo, en este mismo sentido, la extensión del calendario competitivo catalán en el año 1917, organizado por la Federación de Sociedades Deportivas de Barcelona con 153 competiciones diferentes, lo que significó la existencia de 330 días de competición deportiva en un solo año $0^{5}$. Por otro lado, hay que tener en cuenta la incidencia que tuvo en la presencia pública del fenómeno deportivo el aumento de competiciones de gran calado local i general, con ejemplos de indiscutible valor como, en el caso del ciclismo, la Volta a Cataluña (1911), y en otras disciplinas la celebración de los 
primeros campeonatos de Cataluña de atletismo (1916), la primera Copa de Cataluña de remo (1917), las primeras pruebas internacionales de Hípica en el Club de Polo (1919) o la celebración de la primera edición del Gran Premio Jean Bouin de atletismo (1920), que se convirtió en la primera prueba de carácter popular en circuito urbano de España.

En este contexto, el incremento del deporte en los albores de 1914, dio como resultado el planteamiento de nuevas fórmulas periodísticas en la prensa deportiva catalana en general, y una profunda reflexión empresarial en los periódicos de mayor tirada de Barcelona, caso de Stadium y El Mundo Deportivo. En lo que se refiere a Stadium, que a finales de 1913 aseguraba ser "el mejor y a la vez el más popular, el que más se lee y el que tira mayor número de ejemplares" (Stadium, 15-12-1913), su dirección decidió renovar la publicación para el inicio de 1914, gracias al incremento de la publicidad en un momento de creciente demanda. La nueva estructura de la revista en 1914 ofrecía un retrato, sin precedentes en la prensa deportiva española de la época, en relación a las tendencias innovadoras y a la superación de los viejos moldes "ya insuficientes para dar cabida a todo lo que se aglomera sobre nuestras mesas de trabajo" (Stadium, 15-12-1913). En el primer número de 1914, la revista dedicaba 32 páginas a "todos los deportes", un extenso monográfico en el apartado "Revista del Automóvil", y el resto de páginas consagradas a la crónica de "Teatros, gran mundo y modas" (Stadium, 31-01-1914). La revista, además, ofrecía una extensa crónica gráfica en papel couxé. Sin embargo, y a pesar de innovadoras operaciones de marketing como sorteos y regalos a lectores anónimos (Stadium, 17-01-1914), la revista seguía alejada de los nuevos aficionados y deportistas pertenecientes a los sectores populares. El Mundo Deportivo, por su lado, incorporó algunas mejoras técnicas a principios de 1914, como la nueva composición en linotipia, que hacía posible introducir con más facilidad las informaciones de última hora. A pesar de ello, el periódico mantenía una estructura formal tradicional, muy alejada de la profusión gráfica de su competidor. El hecho de que, en febrero de 1914, su director y fundador Narcís Masferrer abandonara el periódico para crear Vida Moderna -que se autodenominaba como revista de "salones, teatros y sport"-, da muestra de algunos cambios en la tendencia de la oferta periodística del momento y de la necesidad de replanteamientos en las plataformas tradicionales de la ciudad.

Con todo, el estallido de la guerra en Europa aceleró las transformaciones inevitables con la aparición de problemas inéditos, entre agosto y octubre de 1914. La movilización de periodistas de origen francés e inglés que trabajaban en la prensa deportiva catalana, la desaparición de informaciones y de las competiciones internacionales, el descenso de contratos de publicidad con empresas -básicamente de automóviles- de origen europeo, o la inicial caída de ventas, obligaron a un replanteamiento de la oferta en un mercado que hasta el momento había sido creciente (Pujadas y Santacana, 1997: 36). En consecuencia, en noviembre de 1914 los periódicos deportivos barceloneses supervivientes -Stadium, El Mundo Deportivo y Vida Moderna- se vieron obligados a pactar una salida empresarial que permitiera racionalizar la oferta en una coyuntura adversa. Tal salida consistió en la creación de una única empresa editorial para la prensa deportiva barcelonesa -Editorial Deportiva, 
SA-, la desaparición de Vida Moderna, y la consolidación de las otras dos cabeceras que serían los únicos semanarios deportivos de la ciudad (Stadium, 30-10-1914). Este cambio de escenario en la oferta de prensa deportiva, posible gracias al entendimiento de Ricard Cabot, Narcís Masferrer y Jaume Grau, que eran los directores de los tres periódicos en cuestión, no solo permitió la supervivencia de los semanarios con más recorrido empresarial, sino que aceleró su adaptación formal y su discurso a la modernización de los años de posguerra. El cambio, además, se realizó con inusitada agilidad. El Mundo Deportivo pasó a ser tirado en rotativa, bajó a 4 páginas, incorporó ilustraciones en la portada y abandonó los artículos doctrinarios, lo cual le permitió modernizarse y llegar a más público. La revista Stadium, por otro lado, diversificó su oferta si bien mantuvo su modernidad visual: pasó a tener 16 páginas, siguió ofreciendo una extensa crónica gráfica y redujo el precio a 20 céntimos. Casi seis años después de su creación, la empresa Editorial Deportiva se disolvió en julio de 1920, cuando había "cumplido ya su misión histórica" (Stadium, 17-07-1920), y en un momento en el que "la propia lógica del desarrollo capitalista empezó a vincular, de manera lenta pero inexorable, deporte y dinero" (Bahamonde, 2011: 104).

Tabla 2. 1914-1920. Aparición de cabeceras deportivas nuevas en Barcelona y Cataluña. Fuente: Elaboración propia

\begin{tabular}{|c|c|c|c|}
\hline Años & Barcelona & Cataluña & Total \\
\hline 1914 & 4 & 5 & 9 \\
\hline 1915 & 2 & 1 & 3 \\
\hline 1916 & 5 & 1 & 6 \\
\hline 1917 & 3 & 1 & 7 \\
\hline 1918 & 9 & 1 & 10 \\
\hline 1919 & 5 & 4 & 9 \\
\hline 1920 & 5 & 3 & 8 \\
\hline Totales & $33(67 \%)$ & $16(33 \%)$ & $49 \quad 100 \%)$ \\
\hline
\end{tabular}

\section{Llega el espectáculo: Masificación deportiva y prensa popular (1920-1936)}

De la misma manera que ocurrió en otros países del Occidente europeo y en Estados Unidos (Wiggins, 1995: 207; Vigarello, 1995: 216), las década de 1920 y 1930 fueron el escenario de profundas transformaciones en el deporte. Sobre todo en lo que se refiere al espectáculo, pero también en su versión practicada, dejó de ser un pasatiempo minoritario para convertirse en uno de los epicentros de la moderna cultura de masas. Lo que Alain Corbin ha definido, para el fútbol de los años 1918 a 1932, como la "etapa de democratización" (1995: 226), fue en realidad un período de emergencia de la cultura del consumo en el que la cultura deportiva se transformó y se masificó (Wiggins, 1995: 207). En este proceso de popularización deportiva, la prensa en general, y la especializada en particular, jugó un papel preponderante en la divulgación del espectáculo y de los nuevos símbolos de la cultura del deporte, adap- 
tándose a nuevos lenguajes, formas y estructuras. Si antes de 1915, el periodismo deportivo debía familiarizar a sus lectores con las disciplinas y sus códigos normativos y técnicos, a partir de 1920 las cabeceras dedicadas al deporte perdieron su carácter didáctico y doctrinario para focalizarse en los protagonistas y sus hazañas. En Italia, como en tantos otros lugares, las primeras biografías de jugadores de fútbol se publicaron a principios de la década (Lafranchi, 2006: 145).

En el caso catalán, el deporte en las décadas de 1920 y 1930 mostró claros síntomas de transformación en la línea de lo que estaba sucediendo en general en Occidente. La confluencia de diferentes factores de popularización y masificación se hicieron visibles, como la proliferación de los deportes espectáculo -entre los que el fútbol y el boxeo ya destacaban poderosamente-, el incremento de la presencia pública de competiciones, el aumento de la red asociativa, la incorporación de nuevas disciplinas, y la creación de grandes estadios para miles de aficionados (Pujadas y Santacana, 1994: 105-106). Este nuevo escenario se vio favorecido por un nuevo periodismo especializado, renovador y expansivo, que sintonizaba con los modelos de modernización de la periodística general, como son la evolución hacia un periódico explicativo, la apertura hacia el cosmopolitismo y la incorporación de nuevas técnicas de redacción y nuevos géneros (Casassús, 1993: 27). No obstante, cabe tener en cuenta que el impacto transformador de la nueva prensa deportiva de la década de 1920 fue tanto cuantitativo como cualitativo. En lo que se refiere a la extensión cuantitativa, la aparición de nuevas publicaciones a partir de 1919 y 1920 puede calificarse de "auténtico boom" (López, 2011: 395), que alcanzó su punto máximo entre 1922 y 1923, con la aparición de 18 y 25 cabeceras deportivas respectivamente, y que disminuyó progresivamente a partir de la segunda mitad de la década y en la etapa republicana (ver gráfico 1). Esta proliferación inédita de títulos, además, se tradujo en un proceso de expansión territorial con el incremento de periódicos editados fuera de Barcelona, hasta alcanzar el 34\% del total de publicaciones deportivas del período. Tal eclosión periodística, sin embargo, no perjudicó a la existencia de secciones deportivas de la prensa general, que adquirieron más protagonismo, fruto del aumento de la demanda de información sobre deporte, que ya se había convertido en el "lado más lúdico y a su vez significativo de la nueva cultura de masas" (Gómez Mompart, 1992: 172). Como consecuencia del ascenso de la demanda informativa y de la creciente actividad deportiva generadora de información escrita, entre enero y octubre de 1923 dos cabeceras especializadas se aventuraron a salir diariamente. Estas experiencias, de escasa duración, fueron las del Diario de Sports (enero, 1923) y del semanario barcelonés La Jornada Deportiva, subtitulado como "Diario Nacional de Sports" en octubre de 1923 (Pujadas y Santacana, 1996: 46). Totalmente distinta fue la fortuna de El Mundo Deportivo, que pasaría a ser bisemanal en 1923 y definitivamente diario en 1929 (Seoane y Saiz, 2007: 196). 
Gráfico 1. 1921-1936. Aparición de cabeceras deportivas nuevas en Cataluña.

Fuente: Elaboración propia

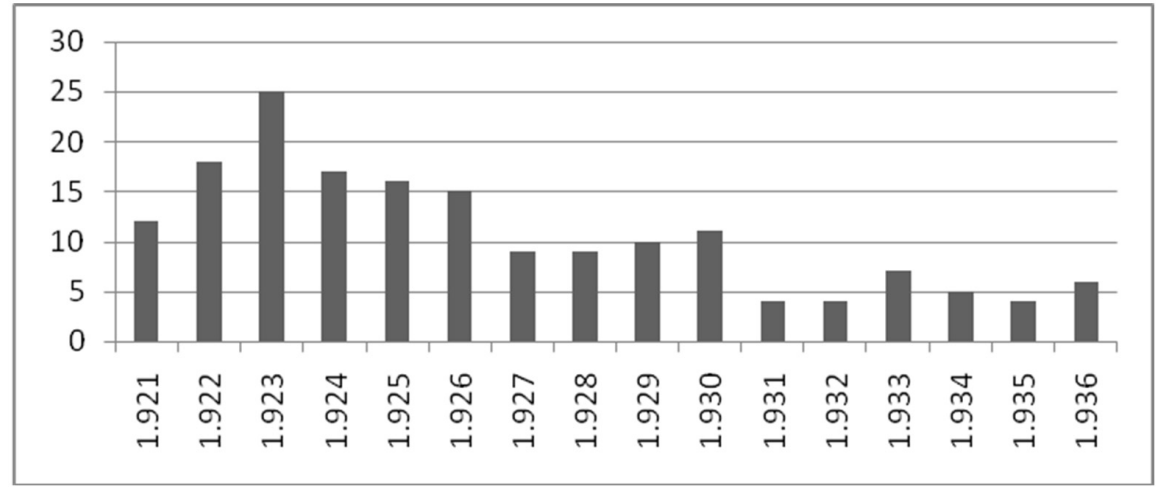

Analizado desde un punto de vista cualitativo, la gran expansión de la prensa deportiva de los años de 1920 permite establecer tres elementos diferenciales respecto de la anterior etapa de transición, que facilitaron un cambio discursivo substancial y permitieron la extensión de la moderna cultura del deporte de masas. En primer lugar debemos referirnos a la especialización por disciplinas del periodista profesionalizado, que ayudó a fijar secciones especializadas y a crear un universo simbólico determinado para cada deporte. Este hecho, sin duda, provocó la progresiva desaparición del periodista sportman generalista a la vieja usanza, cuyo discurso divulgador y doctrinario fue relevante a principios del siglo XX, y empujó a deportistas de renombre a ejercer de cronistas con un conocimiento técnico específico muy superior. En la prensa catalana este proceso fue muy destacado desde principios de la década, con las aportaciones de atletas como Lluís Meléndez (Sports, 1923), Guerau Garcia (Catalunya Atlètica, 1933) y Rossend Calvet (Vida Deportiva, 1921 y L'Esport Català, 1925), de tenistas como Carles Sindreu (L'Esport Català, 1925), nadadores como Antoni Trigo (Aire Libre, 1923) o boxeadores como Federico Zaldívar (Boxeo, 1921).

En segundo lugar, es necesario tener en cuenta la aparición de un nuevo modelo de crónica específicamente deportiva, intelectualmente más rica y con un lenguaje propio, ágil y más moderno. Ante un lector consumidor de espectáculo deportivo cada vez más instruido, la incorporación de una prosa deportiva propia - no solo desde la perspectiva técnica, sino simbólica- aportaba un distintivo que identificaba la prensa deportiva como un espacio comunicativo con un lenguaje específico. Las aportaciones de periodistas como Antoni Vilà en las crónicas de boxeo, de Isidro Corbinos, Josep Lluís Lasplazas, Vicens Bernades o Josep Anton Trabal, entre otros, dotaron el discurso periodístico deportivo de un tono intelectual, reflexivo y estéticamente innovador sin precedentes. Corbinos, que según Narcís Masferrer escribía "fabricando una nueva prosa para el deporte" (La Vanguardia, 2-01-1927), destacó en la creación de La Jornada Deportiva en 1921, un rotativo ilustrado en color que combinaba la moderna crónica deportiva con el discurso regeneracionista y social. 
La gran eclosión de la crónica gráfica -ya ensayada por cabeceras como Stadium en etapas anteriores- y de la prensa especializada en deportes concretos, resultó ser, igualmente, un aspecto novedoso del moderno lenguaje periodístico deportivo. Es interesante, en este sentido, aludir a la irrupción de cabeceras dedicadas al boxeo -Boxeo (1921), Boxeo (1924), El Ring (1925), Box (1929)-, y de magazines ilustrados como Gràfic-Sport (1926), Gaceta Deportiva (1928) y Deportes (1928), que explotaron la actualidad gráfica y el "comentario crítico y anecdótico" (Gràfic-Sport, 21-12-1926), en un contexto en el que la aparición de la radiodifusión estaba acelerando la conversión del deporte, y en especial del fútbol, en un espectáculo de masas (Balsebre, 2001: 235). No hay que olvidar, en este sentido, que Radio Barcelona se ocupó de emitir información deportiva desde diciembre de 1924 con un espacio diario de "Crónica de Deportes" (Seoane y Saiz, 2007: 199).

Finalmente, es imprescindible analizar el auge de la prensa deportiva de la época a partir de la incorporación de géneros y modelos periodísticos nuevos, que combinaban la modernidad formal con perspectivas renovadas acerca del fenómeno deportivo. En el caso de Cataluña, la fuerte irrupción de la prensa humorística deportiva y del periodismo deportivo cívico catalanista -sobre todo al final de la dictadura de Primo de Rivera- facilitaron la llegada de la cultura deportiva a un público más amplio y heterogéneo, popular. Por lo que respecta a la prensa satírica y de caricatura deportiva, la publicación más arraigada fue el semanario en catalán Xut! (1922), creador de un estilo caricaturesco y un universo semántico propios -el universo del Sidral, en referencia a la bebida carbonatada que solían tomar los hinchas del FC Barcelona en los quioscos de refrescos- y que perduró hasta la guerra civil habiendo creado un léxico popular deportivo catalán (Cadena, 1992). Gran parte del éxito del semanario fue la capacidad de llegar, a través del dibujo y del comentario satírico y crítico, a la vertiente humana y más prosaica del deportista, mientras que la prensa deportiva convencional se dedicaba a "glosar el aspecto heroico, patriótico y sublime del fútbol" (Castanys, 1964: 54). El auge de este género, que según algunos autores podría considerarse genuino del periodismo catalán (Amat, 1980: 13), provocó la publicación de múltiples semanarios de características similares, como $\mathrm{Pa}$...nal! (1923), Faut (1924), Orsai (1924), La Barrila Deportiva (1924), Safareig Deportiu (1925), Sidral Deportiu (1925), La Bimba (1926), sin que ninguno encontrara la calidad ni la fórmula del éxito de Xut!.

El desarrollo de un tipo de prensa deportiva que vinculaba el deporte con la defensa de un modelo de sociedad democrática, republicana y catalanista, permitió que el fenómeno deportivo llegase a sectores sociales tradicionalmente alejados de la práctica y el espectáculo de deporte. Sin duda, se trata de un tipo de periodismo ideologizado que respondía a la existencia de un discurso popular deportivo autóctono, interclasista y cercano a los postulados del catalanismo republicano y socializante que culminó en 1931 con la creación de Esquerra Republicana de Catalunya (Pujadas, 2011: 144-146). La aparición del semanario L'Esport Català (1925), que en plena dictadura afirmaba tirar 8000 ejemplares (L'Esport Català, 112-1927) y, sobretodo, de la Nau dels Esports (1929) y su continuadora La Rambla (1930), ponen de relieve la combinación de un discurso deportivo con "cada vez más 
densas derivaciones sociales y políticas" (Uría, 2008: 160). La Rambla, cuyo subtítulo "Esport i Ciutadania" intentaba simbolizar su estrategia ideológica, propició un triple planteamiento popular, catalanista y cultural sin renunciar a las técnicas del periodismo de masas. La Rambla, que abandonaría la temática deportiva y cívica durante la guerra civil, ejemplificó mejor que otras cabeceras la posibilidad de extender la cultura deportiva a través de postulados sociopolíticos populares que, en un escenario prebélico en España, eran seguidos por miles de lectores.

\section{Conclusiones: La prensa como factor de extensión deportiva}

Deporte y periodismo se retroalimentaron constantemente, de tal manera que se puede considerar que la prensa deportiva era el reflejo del nivel de desarrollo de la práctica deportiva, pero también que los actores deportivos corroboraban su papel social a través de la atención periodística que conseguían captar. Más allá, incluso, podemos considerar que en la fase más inicial la prensa especializada formaba parte inexorable del proceso de institucionalización deportiva, ya que una parte esencial de la sociabilidad de las primeras entidades deportivas pasaba necesariamente por sus boletines, que devenían las primeras publicaciones especializadas y el motor organizativo. Imprescindibles para la extensión del discurso de la cultura deportiva.

Estos vasos comunicantes informan con gran detalle del proceso de implantación y desarrollo del deporte, y señalan unas etapas suficientemente diferenciadas, que en el caso catalán corresponderían a tres fases: la primera, hasta la Primera Guerra Mundial, caracterizada en un primer momento, a finales del siglo XIX, por publicaciones vinculadas a clubs y entidades promotoras de un tipo de prácticas concretas, muy especialmente el ciclismo, y también la pelota, que a medida que la práctica se va diversificando da lugar a una prensa especializada pero que va más allá del boletín asociativo, aunque en muchos casos compatibiliza la información general con las noticias estrictamente organizativas. Las cabeceras que responden a este modelo son esencialmente Los Deportes y El Mundo Deportivo, que además promueven competiciones deportivas y plataformas de presión, como el Sindicato de Periodistas Deportivos, no únicamente profesional, sino que actuaba como aglutinante de unos periodistas que se consideraban implicados en el desarrollo del deporte. La conversión del deporte en un espectáculo empieza a confirmarse gracias a la aparición de Stadium en 1911, revista que presagiaba ya una nueva visión, dejando en un segundo plano los elementos del discurso doctrinario y tomando mayor presencia la descripción del espectáculo, que se beneficia enormemente de unas posibilidades gráficas desconocidas hasta ese momento. Stadium anuncia el paso a la segunda fase, de 1914 a 1920, que podemos definir como de transición, y en que el elemento empresarial y económico deviene clave en la consolidación del deporte. De ese modo, la configuración de la prensa deportiva como negocio es definitoria y esencial, acorde con un calendario competitivo en clara progresión y a la extensión social del deporte hacia sectores sociales más mayoritarios, que en el caso catalán pasa también por desbordar la presencia de prensa especializada más allá de Barcelona y Reus. 
Aunque nos referimos de forma preferente a las publicaciones deportivas, en la tercera fase de nuestra cronología (1920-1936) debemos constatar el notable incremento que habían experimentado las secciones deportivas de la prensa general. La información deportiva vinculada al espectáculo y la sociedad de masas ya no podía ser evitada por ningún medio. Estos años son sin duda el momento más álgido de la prensa deportiva catalana, en la que conviven semanarios abiertos a todos los deportes, en general con una notable carga de valores e ideológica; revistas especializadas; publicaciones de base local; un modelo propio de prensa satírica y los intentos por conseguir un periódico de aparición diaria. En ese proceso conviene destacar la progresiva incorporación de la lengua catalana, que como todos los idiomas distintos del inglés tuvo que generar un estándar deportivo, y que en el caso que nos ocupa generó dos registros, uno de los cuáles alimentaba una prensa satírica que se editaba exclusivamente en catalán, y que significaba una de las adaptaciones más evidentes a la nueva cultura de masas. El otro indicador fueron los intentos por editar un diario, fracasados al empezar la década, pero exitoso en 1929 con la conversión a diario de El Mundo Deportivo.

De esta manera se completaba el ciclo iniciado con los boletines y se conformaba un sistema comunicativo suficientemente amplio y variado, que confirmaba las múltiples formas de vivir el deporte, desde la práctica al simple espectáculo, así como el interés de los líderes de opinión, ya fuesen periodistas o intelectuales, por comentar y analizar su significado entre las novedades de una sociedad de masas y en el debate sobre las pautas de modernización social. Un horizonte que acabó abruptamente con la Guerra Civil y la implantación del franquismo, que significó una ruptura con este legado.

\section{Bibliografía}

AMAT, M. (1980). "El periodisme humorístic esportiu va néixer a Catalunya". En L'Avenç, n' 28 , junio, p. 13-14.

BAHAMONDE MAGRO, A. (2011). "La escalada del deporte en España en los orígenes de la sociedad de masas, 1900-1936”. En PUJADAS, X. (Coord.) (2011). Atletas y ciudadanos. Historia social del deporte en España (1870-2010). Madrid: Alianza. p. 89-124.

BALSEBRE, A. (2001). Historia de la radio en España. (1874-1939). Madrid: Cátedra. BERASATEGUI, M ${ }^{\mathrm{a}}$ L. (2000). "Datos para la historia dse la prensa deportiva en Cataluña”. En Revista General deIinformación y Documentación, vol. 10, 1, p. 153169.

BRAKE, L. y DEMOOR, M. (Eds.) (2009). Dictionary of nineteenth-century journalism in Great Britain and Ireland. Ghent: Academia Press.

CADENA, J.M. (1992). "Xut i El Once, dos títols bàsics de la premsa esportiva d'humor". En Annals del Periodisme Català, no 20, Barcelona: CPC. p. 45.

CASASÚS, J.M. (1993). Periodística catalana comparada. Barcelona: Pòrtic / Mèdia.

CASTANYS, V. (1964). La memoria es diverteix. Barcelona: Destino.

CORBIN, A. (1995). "Le destin contrasté du football". En CORBIN, A. (1995). 
L'avènement des loisirs. 1850-1960. Paris: Flammarion. p. 222-226.

DOMÍNGUEZ ALMANSA, A. (2011). "La práctica de la modernidad: orígenes y consolidación de la cultura deportiva en España, 1870-1914". PUJADAS, X. (Coord.) (2011). Atletas y ciudadanos. Historia social del deporte en España (1870-2010). Madrid: Alianza. p. 55-88.

FIGUERES, J.M. (1992). "Notes sobre un segle de revistes i diaris esportius". En Annals del Periodisme Català, $\mathrm{n}^{\circ}$ 20, Barcelona: CPC. p. 22-32.

GARCÍA FERRANDO, M., LAGARDERA, F. Y PUIG, N. (1998). "Cultura deportiva y socialización”. En Sociología del deporte. Madrid: Alianza. p. 69-98.

GÓMEZ MOMPART, J.L. (1992). La gènesi de la prensa de masses a Catalunya (19021923). Barcelona: Pòrtic/Mèdia.

HARVEY, A. (2004). The beginnings of a commercial sporting cultuea in Britain. 17931850. Alderhot: Ashgate Publishing.

IGLÉSIES, J. (1964). Els primers excursionistes. Barcelona: Dalmau.

LAFRANCHI, P (2006). "La Première guerre mondiale et le développement du football en Europe: le cas italien”. En GASTAUT, Y. y MOURLANE, S. (2006). Le football dans nos sociétés (1914-1918). París: Autrement. p. 136-145.

LAGARDERA, F. (1991). Una interpretación de la cultura deportiva entorno a los orígenes del deporte contemporáneo en Cataluña. Tesis doctoral. Universitat de Barcelona, Departamento de Teoría e Historia de la Educación.

LÓPEZ, B. (2011). "El impacto social y cultural del deporte en la España del bienestar: televisión, consumo y deporte mediático, 1982-2000”. En PUJADAS, X. (Coord.) (2011). Atletas y ciudadanos. Historia social del deporte en España (1870-2010). Madrid: Alianza. p. 393-432.

NAVARRO, E. (1916). Álbum histórico de las sociedades deportivas en Barcelona. Barcelona.

PUJADAS, X. (2012): "Sport, Space and the Social Construction of the Modern City: The Urban Impact of Sports Involvement in Barcelona (1870-1923)", The International Journal of the History of Sport, DOI:10.1080/09523367.2012.696348. (2011). "Del barrio al estadio. Deporte, mujeres y clases populares en la Segunda República, 1931-1936". En PUJADAS, X. (Coord.) (2011). Atletas y ciudadanos. Historia social del deporte en España (1870-2010). Madrid: Alianza. p. 125-168. (2004). 'L'aparició d'un nou concepte de lleure. De l'esport elitista a l'espectacle de masses 1890-1936". En Afers. Fulls derecerca i Pensament, 49, 641-656.

PUJADAS, X.; SANTACANA, C. (1994). Història il-lustrada de l'esport a Catalunya (1870-1931). Barcelona: Columna/Diputació de Barcelona.

(1997). L'esport és notícia. Historia de la prensa esportiva a Catalunya (1880-1992). Barcelona: Diputació de Barcelona/Col-legi de Periodistes de Catalunya.

RIESS, S. (1995). Sport in industrial America. 1850-1920. Wheeling: Harlan Davidson.

ROMA, F. (1996). Història social de l'excursionisme català. Dels orígens a 1936. Barcelona: Oikos-Tau.

ROWE, D. (2008). Sport, culture and media. Berkshire: Open University Press.

SEOANE, M.C.; SÁIZ, M.D. (2007). Cuatro siglos de periodismo en España. De los avisos a los periódicos digitales. Madrid: Alianza.

SUBIRATS, O. (2004). "Modernitat i Renaixença. Els orígens de l'excursionisme català". En Afers. Fulls de recerca i pensament, 49, 623-640. 
TORREBADELLA, X. (2012). "Orígenes del fútbol en Barcelona (1892-1903)”. En RICYDE, Revista Internacional de Ciencias del Deporte, 27 (8), 80-102.

URÍA, J. (2008). "Los deportes de masas en los años veinte. Fútbol, élites simbólicas, e imágenes de modernidad en España”. En SALAÜN, S. y ETIENVRE, F. (eds.) La réception des cultures populaires et des cultures de masses en Espagne (XVIIIe-XXe siècle), Paris, Sorbonne Nouvelle-CREC, 2008. [ed. electrónica en http://crec.univparis3.fr/actes/08\%20Uria.pdf ]

VIGARELLO, G. (1995). "Le temps du sport". En CORBIN, A. (1995). L'avènement des loisirs. 1850-1960. Paris: Flammarion. p. 193-221.

WIGGINS, D. (Ed.) (1995). Sport in America. From wicked amusement to National obsession. Champaign: Human Kinetics.

\section{Notas}

1 Nos referimos a L'Excursionista (1878) y al Butlletí de l'Associació d'Excursions Catalana (1878), publicaciones importantes en la difusión del excursionismo científico.

2 Las publicaciones analizadas han sido: El Ciclista (1891), Revista de Sport (1895), El Veloz (1895), La Bicicleta (1896), El Frontón (1893), Los Deportes (1895), El Mundo Deportivo (1906), Stadium (1911), La Jornada Deportiva (1921), Boxeo (1921), Xut! (1922), L’Esport català (1925), Gràfic Sport (1926), Deportes (1928), La nau dels Esports (1929), La Rambla (1930).

3 "Nuestros propósitos", El Ciclista, no 1, 16-07-1891, p. 1.

4 "Resumen o balance ciclista del año 1898", Los Deportes, 15-03-1899.

5 Federación de Sociedades Deportivas: Calendario Deportivo para 1917, Barcelona, 1917.

\section{Los autores}

Xavier Pujadas i Martí es profesor titular de la Universitat Ramon Llull, desde donde dirige el Grupo de Investigación e Innovación Deporte y Sociedad. Es Fellow del Comité Europeo de Historia del Deporte y autor de decenas de artículos y varios libros, ha coordinado la obra Atletas y ciudadanos. Historia social del deporte en España (1870-2010) (Alianza, 2011).

Carles Santacana i Torres forma parte del Grup d'Estudi d'Història de la Cultura i dels Intel•lectuals (GEHCI), y es profesor titular y director del departamento de Historia Contemporánea de la Universitat de Barcelona. Es autor de una extensa bibliografía sobre historia social del deporte e historia cultural y política, entre la que destacan El franquisme i els catalans (2000) y El Barça y el franquismo (2006). 